\title{
54th ISCEV Symposium
}

\section{Welcome Address}

Dear Friends and Colleagues,

On behalf of the ISCEV and Singapore National Eye Centre, we bid all our delegates a very warm welcome to Singapore for the 54th ISCEV International Symposium.

The symposium reflects ISCEV's longstanding commitment to support and promote electrophysiology in all parts of world. It serves as a unique opportunity for electrophysiologists, clinicians, trainees and researchers to engage in a lively, interactive discussion through panel discussions, human and animal courses. It promises to provide a platform to share new knowledge, transfer skills to the participants.

This year's symposium will be held at The Academia's auditorium, an iconic landmark within Singapore General Hospital campus. Through our joint efforts with the international ISCEV committee, we bring to you a scientific program encompassing basic science research to clinical electrophysiology. The Human and animal course will be run by ISCEV team of seasoned educators in collaborations with Singapore Eye Research Institute (SERI) animal facilities at the Academia.

The rapid fire clinical case presentation session will showcase role of electrophysiology in management of challenging cases. We are very pleased to have International vision researchers of eminence delivering Adachi Award (Prof. Michael Bach) and Dawson Lecture (Prof. Wong Tien Yin).

One of the main highlights of the meeting is the ISCEV social program! We will host the welcome reception at the Singapore National Eye Centre with our traditional Lion Dance. We also look forward to healthy dose of competition between all teams during our ISCEV Olympics. The symposium will end with our gala dinner at the Fort Canning Park, which is a unique blend of historical relics and lush greenery.

On behalf of the organizing secretariat, we thank the faculty for the innumerable hours spent preparing their presentations and course material, to provide the most up to date and comprehensive review on the role of electrophysiology in clinical and research. And special thanks to the esteemed members of ISCEV international advisory committee for their invaluable assistance, scientific guidance and judging the scientific sessions.

We would like to take this opportunity to thank all our sponsors for their generosity and hardworking local organizing committee which has been pivotal to the success of this congress.

We wish you a wonderful experience in Singapore and a great meeting ahead.

Audrey Chia and Ranjana Mathur, Local organizers, ISCEV 2016 